\title{
Avaliação do perfil sensorial de chá light sabor pêssego
}

\author{
Sensory profile evaluation of light peach tea
}

\author{
Cibele Cristina OSAWA ${ }^{1}$, Cristhiane Caroline FERRARI ${ }^{1 *}$, Priscila Becker SIQUEIRA ${ }^{1}$, \\ Carlos Alexandre Koguishi de BRITO ${ }^{1}$, Gustavo Braga SANVIDO ${ }^{1}$, Adriana Prais BOTELHO ${ }^{1}$, \\ Leonardo Rangel ALVES ${ }^{1}$, Cláudio Fernandes CARDOSO ${ }^{1}$, Viviane Helena Ferreira MOAIS ${ }^{1}$, \\ Lauro Luís Martins Medeiros de MELO $^{1}$, Ana Paula Badan RIBEIRO ${ }^{1}$, Helena Maria André BOLINI ${ }^{2}$
}

\section{Resumo}

No presente estudo foi determinado o perfil sensorial e a aceitação de três marcas comerciais de chá light sabor pêssego, denominadas A, B e C, acondicionadas em embalagem PET e adquiridas no comércio local. O perfil sensorial foi determinado por Análise Descritiva Quantitativa (ADQ) utilizando-se uma equipe de 11 provadores rigorosamente selecionados e treinados. A aceitação dos produtos foi avaliada por 33 consumidores representativos do público alvo. Os resultados da ADQ foram submetidos à Análise de Variância (ANOVA), Teste de Média de Tukey e Análise de Componentes Principais. As amostras comerciais apresentaram perfis semelhantes em alguns termos descritores e diferenças significativas em outros. A amostra A caracterizou-se principalmente pelos atributos aroma e sabor de banana passa; a amostra B por aroma artificial de pêssego e refrescância; e a amostra C por aroma natural de pêssego e doçura. O Teste Afetivo, analisado por ANOVA e Teste de Média de Tukey, indicou maior aceitação para a amostra C. A cor das amostras foi avaliada pelo método Cielab $L^{\star} a^{*} b^{*}$, sendo que a amostra $\mathrm{C}$ se destacou das demais pela cor vermelha.

Palavras-chave: chá light; pêssego; análise sensorial; análise descritiva quantitativa; teste afetivo.

\begin{abstract}
In this work, three different brands of light peach iced tea (A, B and C), purchased in a local market and packed in PET bottles were sensory analyzed. At first, Quantitative Descriptive Analysis (QDA) was conducted in order to obtain the sensorial profile, with eleven tasters, previously selected and trained. The product acceptance was evaluated by 33 consumers, representing the target public. The QDA results were submitted to ANOVA, Tukey's test and Principal Component Analysis (PCA). The sample A was mainly characterized by banana aroma and flavor; the sample B by artificial peach aroma and refreshment; while the sample C by sweetness and natural peach aroma. The acceptance test, analyzed by ANOVA and Tukey's test, showed a greater acceptance for the sample C. The colour of the samples was evaluated by the Cielab L*a* $\mathrm{b}^{*}$ method and the sample $\mathrm{C}$ stood out by the red colour.

Keywords: light tea; peach; sensory analysis; quantitative descriptive analysis; acceptance test.
\end{abstract}

\section{Introdução}

De acordo com a legislação brasileira, chá pronto para consumo é a bebida obtida pela maceração, infusão ou percolação de folhas e brotos de várias espécies do gênero "Thea" (Thea sinensis e outras) ou de folhas, hastes, pecíolos e pedúnculos de erva-mate da espécie "llex paraguariensis" ou, ainda, de outros vegetais previstos nos padrões de identidade e qualidade. Admite-se, também, que outras substâncias de origem vegetal e açúcares sejam adicionados (BRASIL, 1997).

Para ser considerada uma bebida de baixa caloria, o chá deve atender a algumas exigências, quanto ao teor de calorias e açúcares. Deve ser uma bebida não-alcoólica e hipocalórica e ter o conteúdo de açúcares normalmente adicionado na bebida convencional substituído por edulcorantes hipocalóricos ou não-calóricos, sejam eles naturais ou artificiais (BRASIL, 1999).
Existem diversos trabalhos na literatura referentes a chá preto adoçado com diferentes edulcorantes. Cardello (2001) estudou a aceitação de chá preto em pó solúvel adoçado com aspartame, estévia e ciclamato/sacarina e sacarose por indivíduos que praticaram exercício físico antes de consumir o chá. Cardoso e Cardello (2003) avaliaram amostras adoçadas com aspartame, ciclamato/sacarina, estévia e sucralose através de terminologia descritiva, utilizando o Método de Rede - Kelly's Repertory Grid Method (MOSKOWITZ, 1983). Cardoso, Battochio e Cardello (2004) determinaram a equivalência de doçura e poder edulcorante de adoçantes em função da temperatura de consumo de bebidas preparadas com chá-mate em pó solúvel.

Os objetivos deste trabalho foram: i) aplicar a Análise Descritiva Quantitativa para traçar o perfil sensorial de três amostras comerciais de chá gelado light sabor pêssego, adoçados

${ }^{1}$ Faculdade de Engenharia de Alimentos, Universidade Estadual de Campinas - UNICAMP, E-mail: criscaferrari@gmail.com

${ }^{2}$ Laboratório de Análise Sensorial, Departamento de Alimentos e Nutrição, Faculdade de Engenharia de Alimentos - FEA, Universidade Estadual de Campinas - UNICAMP, Campinas - SP, Brasil, E-mail: hellini@fea.unicamp.br

${ }^{*}$ A quem a correspondência deve ser enviada 
com edulcorantes diversos em diferentes associações e teores; e ii) avaliar o grau de aceitação das amostras e a atitude de compra dos consumidores.

\section{Material e métodos}

\subsection{Material}

Amostras de chá gelado light sabor pêssego de três diferentes marcas comerciais, acondicionadas em embalagens PET de $1 \mathrm{~L}$ foram adquiridas no mercado e identificadas pelas letras A, B e C, conforme descrição na Tabela 1 .

Para os testes sensoriais, $25 \mathrm{~mL}$ de cada amostra foram servidos, a $15^{\circ} \mathrm{C}$, em copos plásticos descartáveis transparentes $(50 \mathrm{~mL})$ codificados com números de três dígitos aleatórios. Os testes foram realizados no Laboratório de Análise Sensorial da Faculdade de Engenharia de Alimentos da Universidade Estadual de Campinas (UNICAMP), em cabines individuais, e as amostras foram apresentadas de forma monádica em ordem balanceada.

\subsection{Análise sensorial}

\section{Análise descritiva e quantitativa}

O perfil sensorial das amostras foi determinado por Análise Descritiva Quantitativa (STONE; SIDEL, 1993).

Uma equipe de 15 provadores iniciou a Análise Descritiva Quantitativa com o desenvolvimento da terminologia descritiva, através do Método de Rede de Kelly - Kelly’s Repertory Grid Method (MOSKOWITZ, 1983). Gerou-se, assim, a ficha de Avaliação das Amostras (Figura 1) para os termos descritores dos atributos aparência, aroma, sabor e textura. Após seis sessões de treinamento para formação da memória sensorial dos provadores, foram selecionados onze provadores que apresentaram poder de discriminação entre as amostras, repetibilidade nas determinações para cada termo descritor e concordância entre os membros da equipe.

Para isto, foi realizada análise de variância (ANOVA) com duas fontes de variação (amostra e repetição) para cada atributo e para cada provador. Foram então obtidos os valores de $\mathrm{F}$ e $\mathrm{F}_{\text {repetição }}$ para cada provador.

Os provadores aptos a realizar as análises apresentaram $\mathrm{F}_{\text {amostra }}$ significativo para $\mathrm{p}<0,30, \mathrm{~F}_{\text {repetição }}$ não significativo para p > 0,05 e concordância das médias com as da equipe.

Os provadores selecionados avaliaram as amostras realizando três repetições, com auxílio da ficha definida para o teste

Tabela 1. Amostras utilizadas nos testes sensoriais.

\begin{tabular}{cl}
\hline Amostra & \multicolumn{1}{c}{$\begin{array}{c}\text { Edulcorantes utilizados (de acordo com } \\
\text { indicação no rótulo para } 100 \mathrm{~mL} \text { de chá) }\end{array}$} \\
\hline $\mathrm{A}$ & $\begin{array}{l}\text { Ciclamato de sódio }(25 \mathrm{mg}) \text {, aspartame }(6,2 \mathrm{mg}), \\
\text { acessulfame } \mathrm{K}(5,3 \mathrm{mg}) \text { e sacarina }(3 \mathrm{mg})\end{array}$ \\
$\mathrm{B}$ & Aspartame $(22 \mathrm{mg})$ e acessulfame $\mathrm{K}(7,2 \mathrm{mg})$ \\
$\mathrm{C}$ & Ciclamato $(50 \mathrm{mg})$ e sacarina $(6 \mathrm{mg})$
\end{tabular}

(Figura 1). As amostras foram servidas em blocos completos balanceados (MACFIE; BRATCHELL, 1989) e de forma monádica (STONE; SIDEL, 1993).

É importante destacar que as escalas esquematizadas na Figura 1, quando em tamanho original, apresentam $9 \mathrm{~cm}$ de comprimento. Além disso, os testes foram realizados em cabines individuais, sob luz branca (MEILGAARD; CIVILLE; CARR, 1999).

Os resultados gerados na análise sensorial foram avaliados por análise de variância, teste de média de Tukey e análise de componentes principais, utilizando-se o programa estatístico SAS (2003).

\section{Teste de aceitação, atitude de compra e intensidade de doçura}

As mesmas amostras de chá light sabor pêssego foram avaliadas quanto à aceitação entre consumidores habituais desta bebida. Participaram do teste 33 consumidores, número de provadores baseado em Meilgaard, Civille e Carr (1999), que avaliaram os atributos aparência, aroma, sabor e aceitação global utilizando uma escala hedônica de 9 pontos, ancorada

Nome: Data:

Amostra:
Aparência:

Cor de caramelo:

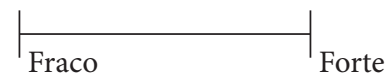

Turbidez:

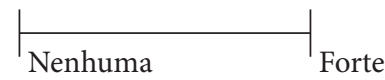

Aroma:

Banana passa:

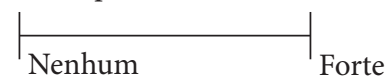

Erva mate:

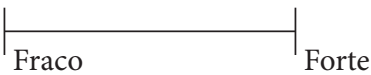

Açúcar queimado:

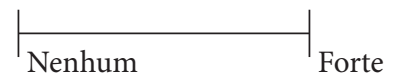

Artificial de pêssego:

Natural de pêssego:

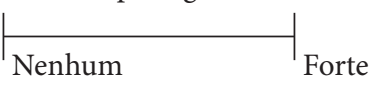

Sabor:

Doçura:

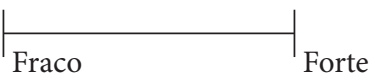

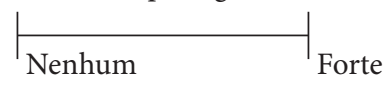

Acidez:

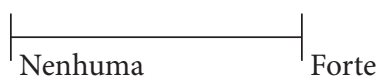

Amargor:

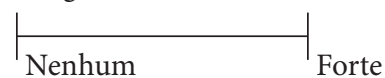

Pêssego:

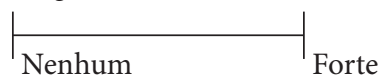

Banana:

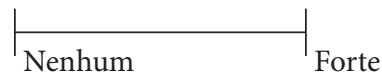

Chá mate:

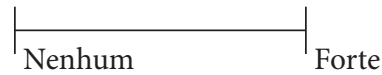

Adstringência:

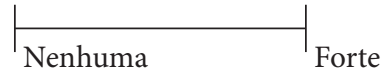

Refrescância:

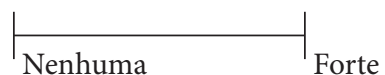

Textura:

Corpo:

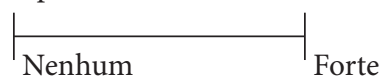

Figura 1. Modelo de ficha empregada na análise descritiva quantitativa. 
nos extremos pelos termos “desgostei muitíssimo" à esquerda e "gostei muitíssimo" à direita (Figura 2).

Avaliou-se também a atitude de compra, em escala de 5 pontos (MEILGAARD, CIVILLE; CARR, 1999), e a intensidade ideal da doçura de cada amostra, utilizando a escala de 9 pontos “just-about-right” (VICKERS, 1988).

\subsection{Análise instrumental de cor}

As cores das amostras de chá foram avaliadas através do sistema de leitura de três parâmetros, o CIELAB, proposto pela Comission Internacionale de I'Eclairage (CIE) em 1971. Os parâmetros $\mathrm{L}^{*}, \mathrm{a}^{*} \mathrm{e} \mathrm{b}^{*}$ foram fornecidos pelo espectrofotômetro de bancada Color Quest II, marca Hunter Lab (Reston, EUA), em que $\mathrm{L}^{*}$ define a luminosidade $\left(\mathrm{L}^{*}=0\right.$ preto e $\mathrm{L}^{\star}=100$ branco) e $\mathrm{a}^{\star} \mathrm{e} \mathrm{b}^{\star}$ são responsáveis pela cromaticidade $\left(+\mathrm{a}^{\star}\right.$ vermelho $\mathrm{e}$ $-a^{\star}$ verde, $+b^{*}$ amarelo e $-b^{*}$ azul). O modelo de calibração utilizado foi o de Reflectância de Transmissão Regular (RTRAN), com uma fonte de iluminação D65 e ângulo de observação de $10^{\circ}$, que é adequado para amostras não totalmente translúcidas, porém que permitem a passagem de luz, como é o caso do chá de pêssego (CALVO; DURAN, 1997).

Esta análise instrumental foi realizada a fim de verificar uma possível correspondência com as avaliações sensoriais (ADQ e aceitação) em relação à aparência do produto.

\section{Resultados e discussão}

\subsection{Análise descritiva quantitativa}

Quinze provadores participaram das sessões do levantamento dos termos descritores, sendo definidos, por consenso da equipe, os atributos relacionados na Tabela 2, com suas respectivas referências, através do Método de Rede - Kelly's Repertory Grid Method (MOSKOWITZ, 1983).

A utilização do atributo textura para uma bebida foi também reportada nos trabalhos de Santana et al. (2006) e VerrumaBernardi e Spoto (2003) que estudaram, respectivamente, o perfil sensorial de iogurte light de pêssego e suco de laranja.

Para a classificação dos termos adstringência e refrescância como propriedades de sabor, levou-se em consideração a definição de "sabor" da ABNT (1993) como sendo a experiência mista, porém unitária, de sensações olfativas, gustativas e táteis percebidas durante a degustação, influenciadas pelos efeitos táteis, térmicos, dolorosos e/ou cinestésicos.

Moraes (2004), Santana et al. (2006) e Cardello e Faria (1998) utilizaram o termo "adstringência" como propriedade de sabor em seus trabalhos com iogurte de morango, aguardente de cana e iogurte light de pêssego, respectivamente, baseandose na ABNT (1993).

Com relação aos termos aroma e sabor de banana passa, é estranho encontrar este tipo de aroma e sabor em chá sabor pêssego, entretanto, na ADQ quem define os atributos sensoriais e a intensidade destes nos alimentos em teste é a equipe sensorial. Deste modo, não foi encontrada nenhuma referência

Nome: $\quad$ Data:__ Amostra:__ Idade:___

Bem-vindo ao Laboratório de Análise Sensorial. Você avaliará 3 amostras de chá gelado sabor pêssego.

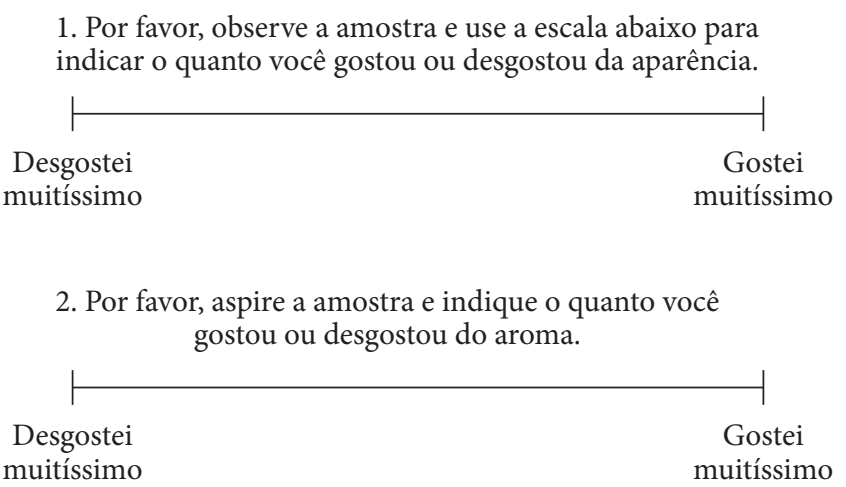

3. Por favor, prove a amostra, e com relação ao sabor, indique o quanto você gostou ou desgostou da amostra.

$\begin{array}{cc}\text { Desgostei } & \text { Gostei } \\ \text { muitíssimo } & \text { muitíssimo }\end{array}$

5. Avalie a doçura da amostra de chá e indique, utilizando a escala abaixo, o quão próxima do ideal encontra-se a doçura da amostra.
( ) Extremamente menos doce que o ideal
( ) Muito menos doce que o ideal
( ) Moderadamente menos doce que o ideal
( ) Ligeiramente menos doce que o ideal
( ) Ideal
( ) Ligeiramente mais doce que o ideal
( ) Moderadamente mais doce que o ideal
( ) Muito mais doce que o ideal
( ) Extremamente mais doce que o ideal

6. Se esta amostra estivesse à venda, qual seria sua atitude?
( ) Certamente não compraria
( ) Provavelmente não compraria
( ) Tenho dúvida se compraria ou não
( ) Provavelmente compraria
( ) Certamente compraria

Figura 2. Modelo da ficha empregada no teste de consumidor (as escalas possuem $9 \mathrm{~cm}$ em tamanho original). 
Osawa et al.

Tabela 2. Definição dos termos descritores de chá gelado light sabor pêssego e referências utilizadas pelos provadores nos testes de Análise Descritiva Quantitativa.

\begin{tabular}{|c|c|c|}
\hline Descritores & Definição & Intensidade \\
\hline \multicolumn{3}{|l|}{ Aparência } \\
\hline Caramelo & Cor característica de açúcar caramelizado & $\begin{array}{l}\text { - Fraco: Glucose de milho (Karo - Unilever) } \\
\text { - Forte: Calda de caramelo (Du Porto) }\end{array}$ \\
\hline Turbidez & $\begin{array}{l}\text { Grau de opacidade da solução na qual } \\
\text { não há transmissão de luz }\end{array}$ & $\begin{array}{l}\text { - Nenhum: } 1 \text { sachê de chá preto marca Leão em } 500 \text { mL de água em ebulição } \\
\text { por } 5 \text { minutos } \\
\text { - Forte: Solução a 2,5\% de limão em chá preto sabor pêssego marca Leão }\end{array}$ \\
\hline \multicolumn{3}{|l|}{ Aroma } \\
\hline Banana passa & Aroma característico de banana passa & $\begin{array}{l}\text { - Nenhum: Água } \\
\text { - Forte: Banana passa }\end{array}$ \\
\hline Chá preto & Aroma característico de chá preto & $\begin{array}{l}\text { - Fraco: Infusão de } 1 \text { sachê de chá preto marca Royal Blend em } 500 \mathrm{~mL} \text { de } \\
\text { água em ebulição por } 5 \text { minutos } \\
\text { - Forte: Infusão de } 3 \text { sachês de chá preto marca Royal Blend em } 500 \mathrm{~mL} \text { de } \\
\text { água em ebulição por } 10 \text { minutos }\end{array}$ \\
\hline Açúcar queimado & $\begin{array}{l}\text { Aroma característico de açúcar queimado } \\
\text { a } 200^{\circ} \mathrm{C} \text { por } 2 \text { minutos }\end{array}$ & $\begin{array}{l}\text { - Nenhum: Água } \\
\text { - Forte: } 50 \mathrm{~g} \text { de açúcar queimado a } 200{ }^{\circ} \mathrm{C} \text { por } 2 \text { minutos }\end{array}$ \\
\hline Artificial de pêssego & Aroma característico artificial de pêssego & $\begin{array}{l}\text { - Nenhum: Água } \\
\text { - Forte: Solução a 0,1\% de essência de pêssego em água }\end{array}$ \\
\hline Natural de pêssego & Aroma característico natural de pêssego & $\begin{array}{l}\text { - Nenhum: Água } \\
\text { - Forte: Néctar de pêssego marca Maguary }\end{array}$ \\
\hline \multicolumn{3}{|l|}{ Sabor } \\
\hline Doçura & Gosto característico de sacarose & $\begin{array}{l}\text { - Fraco: Solução a } 0,8 \% \text { de sacarose em água } \\
\text { - Forte: Solução a } 9,2 \% \text { de sacarose em água }\end{array}$ \\
\hline Acidez & Gosto característico de ácido cítrico & $\begin{array}{l}\text { - Nenhum: Água } \\
\text { - Forte: Solução a 0,03\% de ácido cítrico em água }\end{array}$ \\
\hline Amargor & $\begin{array}{l}\text { Gosto amargo característico presente em } \\
\text { solução de cafeína }\end{array}$ & $\begin{array}{l}\text { - Nenhum: Água } \\
\text { - Forte: Solução a 0,06\% de cafeína em água }\end{array}$ \\
\hline Pêssego & $\begin{array}{l}\text { Sabor característico de suco concentrado } \\
\text { de pêssego marca Maguary }\end{array}$ & $\begin{array}{l}\text { - Nenhum: Água } \\
\text { - Forte: Néctar de pêssego marca Maguary }\end{array}$ \\
\hline Banana passa & Sabor característico de banana passa & $\begin{array}{l}\text { - Nenhum: Água } \\
\text { - Forte: Banana passa }\end{array}$ \\
\hline Chá preto & Sabor característico de chá preto & $\begin{array}{l}\text { - Nenhum: Água } \\
\text { - Forte: Infusão de } 3 \text { sachês de chá preto marca Royal Blend em } 500 \text { mL de } \\
\text { água em ebulição por } 10 \text { minutos }\end{array}$ \\
\hline Adstringência & $\begin{array}{l}\text { Sensação bucal resultante da ação de } \\
\text { compostos fenólicos que causam "amar- } \\
\text { ração" }\end{array}$ & $\begin{array}{l}\text { - Nenhum: Água } \\
\text { - Forte: Solução a 0,05\% de ácido tartárico em água }\end{array}$ \\
\hline Refrescância & Sensação de frescor & $\begin{array}{l}\text { - Nenhum: Água } \\
\text { - Forte: Solução a 0,01\% de essência de menta em água }\end{array}$ \\
\hline \multicolumn{3}{|l|}{ Textura } \\
\hline Corpo & $\begin{array}{l}\text { Sensação de preenchimento da cavidade } \\
\text { bucal }\end{array}$ & $\begin{array}{l}\text { - Nenhum: Água } \\
\text { - Forte: Solução a } 14,5 \% \text { de sacarose em água }\end{array}$ \\
\hline
\end{tabular}

na literatura suportando o emprego destes termos descritivos na avaliação do perfil sensorial de chá light sabor pêssego.

A Tabela 3 apresenta as médias de cada atributo e as respectivas abreviações das marcas avaliadas (A, B e C). A Figura 3 representa o gráfico aranha.

Analisando a Tabela 3, observa-se que não houve diferença significativa entre as amostras para os atributos aroma de chá preto e de açúcar queimado, acidez, amargor e adstringência.

Na Figura 3, pode-se observar que quanto maior a sobreposição das amostras, maior é a semelhança entre si.

Os atributos que mais se destacaram na amostra $\mathrm{A}$, diferindo-a das demais, foram aroma e sabor de banana passa; enquanto que o atributo sabor natural de pêssego foi menos pronunciado.

Já a amostra B apresentou maior intensidade para os atributos aroma artificial de pêssego e refrescância, em relação às demais amostras.

A amostra C, por sua vez, caracterizou-se por apresentar maiores intensidades de doçura e aroma natural de pêssego e menor intensidade de cor caramelo, turbidez e corpo.

A representação gráfica da Análise de Componentes Principais (ACP) está representada na Figura 4. A repetibilidade do método foi estudada, uma vez que os provadores selecionados para a etapa da ADQ avaliaram as amostras, realizando três 
Tabela 3. Perfil sensorial das amostras de chá light sabor pêssego em relação a cada atributo.

\begin{tabular}{|c|c|c|c|c|c|}
\hline Atributo & A & $\mathrm{B}$ & $\mathrm{C}$ & $\mathrm{F}_{\text {Calculado }}$ & P-valor \\
\hline \multicolumn{6}{|l|}{ Aparência } \\
\hline Cor caramelo (CAR) & $5,8^{\mathrm{a}}$ & $5,8^{\mathrm{a}}$ & $2,4^{\mathrm{b}}$ & 272,6 & $<0,0001^{\star * x}$ \\
\hline Turbidez (TUR) & $3,8^{\mathrm{a}}$ & $3,2^{\mathrm{a}}$ & $1,3^{\mathrm{b}}$ & 42,5 & $<0,0001^{\star * \star}$ \\
\hline \multicolumn{6}{|l|}{ Aroma } \\
\hline Banana passa (BAP) & $3,5^{\mathrm{a}}$ & $0,7^{\mathrm{b}}$ & $1,2^{\mathrm{b}}$ & 109,0 & $<0,0001^{* * x}$ \\
\hline Chá preto $(\mathrm{CHP})$ & $1,9^{\mathrm{a}}$ & $2,2^{\mathrm{a}}$ & $1,9^{\mathrm{a}}$ & 2,1 & 0,1301 \\
\hline Açúcar queimado (ACQ) & $2,1^{\mathrm{a}}$ & $1,7^{\mathrm{a}}$ & $2,2^{\mathrm{a}}$ & 2,9 & 0,0642 \\
\hline Artificial de pêssego (ARP) & $3,7^{\mathrm{b}}$ & $4,9^{\mathrm{a}}$ & $3,4^{\mathrm{b}}$ & 25,0 & $<0,0001^{\star * \star}$ \\
\hline Natural de pêssego (NAP) & $2,4^{\mathrm{c}}$ & $2,9^{b}$ & $3,7^{\mathrm{a}}$ & 19,1 & $<0,0001^{\star * x}$ \\
\hline \multicolumn{6}{|l|}{ Sabor } \\
\hline Doçura (DOC) & $3,9^{\mathrm{b}}$ & $4,2^{\mathrm{b}}$ & $5,0^{\mathrm{a}}$ & 11,7 & $<0,0001^{\star * x}$ \\
\hline Acidez (ACI) & $3,7^{\mathrm{a}}$ & $3,4^{\mathrm{a}}$ & $3,4^{\mathrm{a}}$ & 0,7 & 0,4857 \\
\hline Amargor (AMR) & $3,0^{\mathrm{a}}$ & $2,4^{\mathrm{a}}$ & $2,8^{\mathrm{a}}$ & 3,0 & 0,0594 \\
\hline Pêssego (PES) & $2,0^{\mathrm{b}}$ & $3,8^{\mathrm{a}}$ & $4,0^{\mathrm{a}}$ & 45,3 & $<0,0001^{\star * x}$ \\
\hline Banana passa (BAN) & $3,0^{\mathrm{a}}$ & $1,0^{\mathrm{b}}$ & $1,3^{\mathrm{b}}$ & 106,3 & $<0,0001^{\star \star \star}$ \\
\hline Chá preto (CHÁ) & $2,3^{\mathrm{b}}$ & $2,8^{\mathrm{a}}$ & $2,5^{\mathrm{ab}}$ & 4,1 & $0,0212^{\star}$ \\
\hline Adstringência (ADS) & $3,7^{\mathrm{a}}$ & $2,9^{\mathrm{a}}$ & $2,9^{\mathrm{a}}$ & 0,9 & 0,4177 \\
\hline Refrescância (REF) & $2,5^{\mathrm{b}}$ & $3,7^{\mathrm{a}}$ & $2,7^{\mathrm{b}}$ & 31,0 & $<0,0001^{\star * x}$ \\
\hline \multicolumn{6}{|l|}{ Textura } \\
\hline Corpo (CRP) & $3,5^{\mathrm{a}}$ & $3,2^{\mathrm{a}}$ & $2,5^{\mathrm{b}}$ & 14,0 & $<0,0001^{\star * x}$ \\
\hline
\end{tabular}

Letras iguais na mesma linha não indicam diferença estatística entre as amostras no nível de significância avaliado, segundo o Teste de Tukey; ${ }^{*}$ significante a $5 \%$; ${ }^{* * *}$ significante a $0,1 \%$.

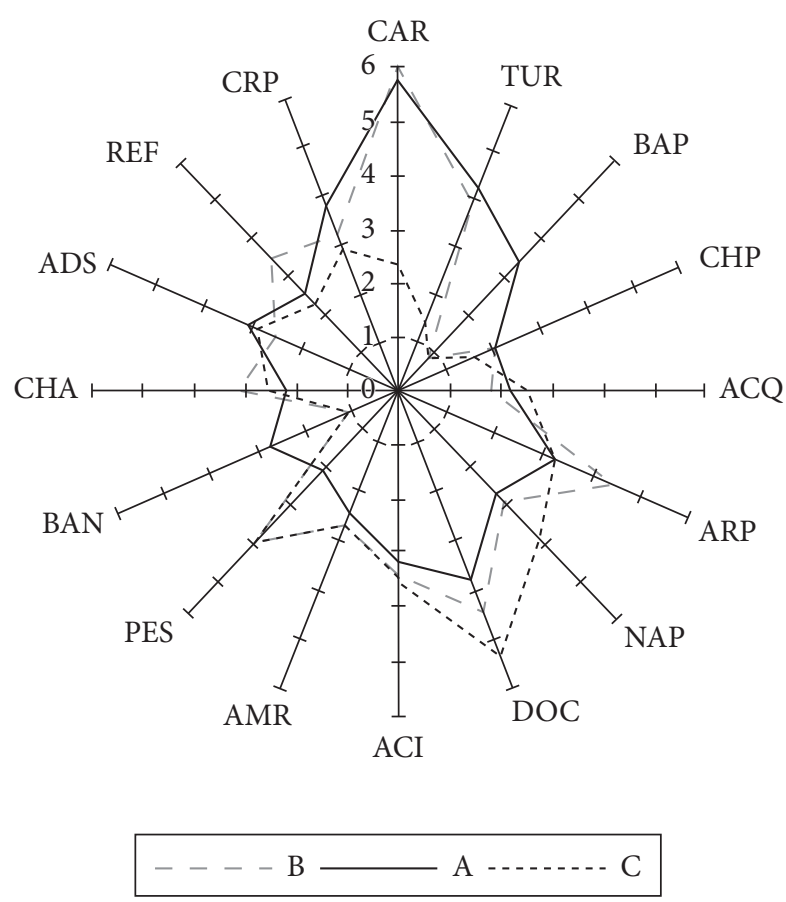

Figura 3. Representação gráfica dos resultados da Análise Descritiva Quantitativa de chá light sabor pêssego para as amostras A, B e C.

repetições. Os resultados de cada amostra de chá e suas repetições são representados por três pontos ligados, formando um triângulo. Cada vértice do triângulo corresponde ao ponto de uma das repetições atribuídas pela equipe sensorial. Tal metodologia também foi utilizada por Battochio et al. (2006), Santana et al. (2006) e Bispo et al. (2005) em seus trabalhos de avaliação
Análise de componentes principais $(72,48)$

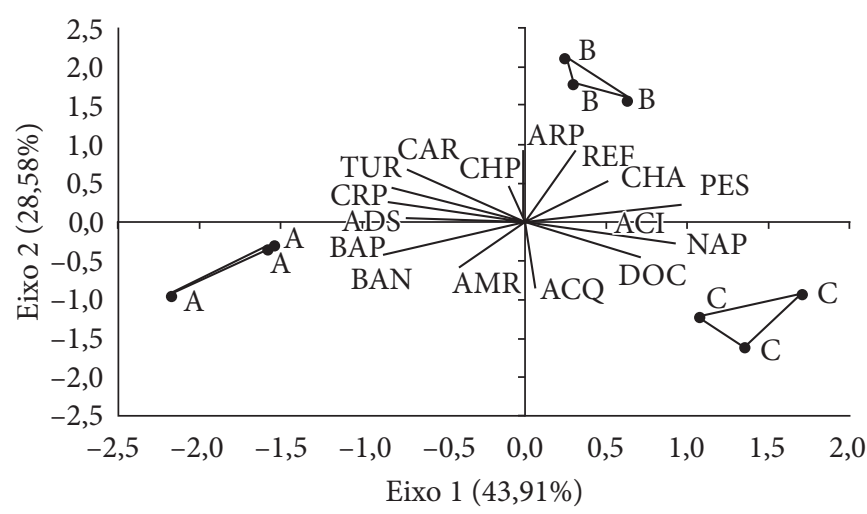

Figura 4. Projeção bidimensional da Análise de Componentes Principais dos termos descritores das três amostras de chá light sabor pêssego (A, B e C).

do perfil sensorial de iogurte light sabor pêssego, pão de forma integral e pó de cacau, respectivamente. No presente trabalho, observou-se uma repetibilidade razoável, evidenciada pelo agrupamento dos pontos representativos de cada amostra.

A distinção entre as amostras pode ser observada pela localização bem definida de cada amostra no gráfico. Verificou-se que $43,9 \%$ da variação ocorrida entre as amostras foi explicada pelo primeiro eixo (Componente principal 1), caracterizado principalmente em relação aos descritores PES e NAP; e 28,6\% pelo segundo (Componente principal 2), caracterizado principalmente em relação aos descritores ARP e REF. Os Componentes principais 1 e 2 explicaram juntos $72,5 \%$ da variação entre as amostras. 
Os descritores são representados como vetores (atributos). Os vetores que ao serem decompostos em um eixo CP apresentam-se como um vetor longo, explicando mais a variabilidade entre os produtos mostrados naquele CP.

$\mathrm{Na}$ ACP, as amostras localizaram-se próximas dos vetores que as caracterizam. Portanto, a amostra A caracterizou-se por BAP e BAN; a amostra B por ARP e REF; e a amostra C por NAP e DOC, confirmando os resultados observados na Figura 4.

\subsection{Teste afetivo}

Não foi verificada diferença significativa $(\mathrm{p} \leq 0,05)$ entre as amostras para o atributo aparência. No entanto, a amostra B apresentou uma maior concentração de notas entre 7,0 e 9,0 para esse atributo.

Em relação aos atributos aroma, sabor e impressão global, a amostra $\mathrm{C}$ apresentou as maiores médias diferindo significativamente $(\mathrm{p} \leq 0,05)$ da amostra A. Tal fato confirma a importância dada pelo consumidor aos atributos NAP e DOC, os quais caracterizaram a amostra $\mathrm{C}$ (Tabela 4 ). Esta também se destaca por apresentar médias próximas ou superiores a 4,5, valor central da escala utilizada, representando, assim, aceitação positiva.

Os atributos sabor e impressão global destacaram-se por apresentar médias inferiores a 5,0 para todas as amostras, encontrando-se na faixa "nem gostei/nem desgostei" da escala hedônica (Tabela 4).

As amostras apresentaram intensidade de doçura próxima ao ideal, exceto a amostra A, que apresentou mais de $70 \%$ das respostas como abaixo do ideal de doçura (Figura 5).

A análise do histograma para atitude de compra sugere maior intenção de compra para a amostra C, uma vez que aproximadamente $60 \%$ das respostas encontram-se na região compreendida entre as opções "tenho dúvida se compraria ou não" e "certamente compraria" (Figura 5).

\subsection{Análise instrumental de cor}

De acordo com a Tabela 5 , pode-se afirmar que a amostra $C$ apresentou menores valores para o parâmetro $b^{\star}\left(+b^{\star}\right.$ amarelo $\mathrm{e}-\mathrm{b}^{\star}$ azul) e maiores valores de luminosidade. Isto corrobora com o resultado da Análise Descritiva Quantitativa, em que a amostra $\mathrm{C}$ apresentou as menores médias de cor caramelo e de turbidez, diferindo significativamente das demais ( $\mathrm{p} \leq 0,05)$. Além disso, a cor vermelha é mais expressiva na amostra C, devido aos valores superiores do parâmetro de cromaticidade $\mathrm{a}^{*}$ em relação à amostra $\mathrm{A}$.

Tabela 4. Médias de aceitação das amostras de chá light em relação a aparência (APA), aroma (ARO), sabor (SAB) e impressão global (IPG).

\begin{tabular}{ccccc}
\hline Atributo & A & B & C & P-valor \\
\hline APA & $5,85^{\mathrm{a}}$ & $5,92^{\mathrm{a}}$ & $6,30^{\mathrm{a}}$ & $0,5127^{\mathrm{ns}}$ \\
ARO & $5,00^{\mathrm{b}}$ & $5,54^{\mathrm{ab}}$ & $6,17^{\mathrm{a}}$ & $0,0352^{*}$ \\
SAB & $3,19^{\mathrm{b}}$ & $3,37^{\mathrm{ab}}$ & $4,47^{\mathrm{a}}$ & $0,0192^{*}$ \\
IPG & $3,61^{\mathrm{b}}$ & $3,89^{\mathrm{ab}}$ & $4,87^{\mathrm{a}}$ & $0,0239^{*}$ \\
\hline
\end{tabular}

Letras iguais na mesma linha indicam que não existe diferença estatística entre as amostras a 5\% de significância, segundo o teste de Tukey; ${ }^{*}$ Nível de significância da diferença estatística; e ns = diferença não significativa.
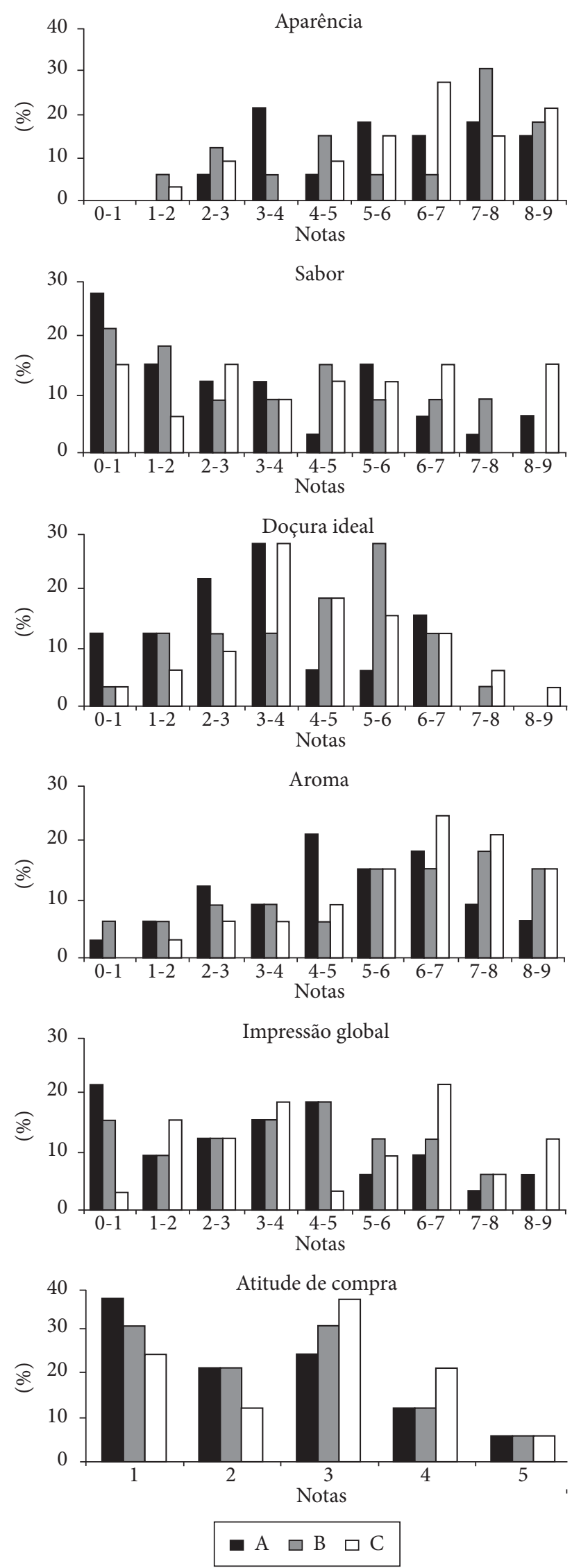

Figura 5. Histogramas de distribuição de notas para o teste de aceitação. 
Tabela 5. Avaliação da cor do chá light sabor pêssego.

\begin{tabular}{cccc}
\hline Amostra & $\mathrm{L}^{*}$ & $\mathrm{a}^{*}$ & $\mathrm{~b}^{*}$ \\
\hline A & $40,92^{\mathrm{a}}$ & $18,08^{\mathrm{a}}$ & $63,30^{\mathrm{a}}$ \\
B & $52,06^{\mathrm{b}}$ & $24,17^{\mathrm{b}}$ & $60,53^{\mathrm{b}}$ \\
C & $63,43^{\mathrm{c}}$ & $24,94^{\mathrm{b}}$ & $58,88^{\mathrm{c}}$ \\
\hline
\end{tabular}

Letras iguais na mesma linha indicam que não existe diferença estatística entre as amostras a 5\% de significância, segundo o teste de Tukey.

\section{Conclusões}

De acordo com os resultados obtidos, foi possível concluir que:

- A amostra C (adoçada com ciclamato e sacarina), caracterizada principalmente por aroma natural de pêssego e gosto doce, foi a que obteve maior aceitação em relação ao aroma, sabor e impressão global, não diferindo da amostra B (adoçada com aspartame e acessulfame-K);

- A amostra A (adoçada com ciclamato, aspartame, acessulfame-K e sacarina) apresentou médias significativamente inferiores à amostra $\mathrm{C}$, embora não tenha diferido significativamente da amostra B;

- A amostra C apresentou maior intenção de compra, uma vez que aproximadamente $60 \%$ das respostas encontraram-se na região compreendida entre as opções "tenho dúvida se compraria ou não" e "certamente compraria";

- De acordo com a Análise de Componentes Principais, a amostra A foi caracterizada principalmente por aroma e sabor de banana passa, enquanto que a amostra $B$ caracterizou-se principalmente por aroma artificial de pêssego e refrescância; e

- A análise instrumental de cor concordou com os resultados da ADQ, em relação aos atributos de aparência, cor caramelo e turbidez.

\section{Referências bibliográficas}

ABNT - ASSOCIAÇÃO BRASILEIRA DE NORMAS TÉCNICAS. NBR12806. Análise Sensorial de Alimentos e Bebidas: terminologia. São Paulo: Comitê Brasileiro de Alimentos e Bebidas,1993.

BATTOCHIO, J. R.; CARDOSO, J. M. P.; KIKUCHI, M. et al. Perfil sensorial de pão de forma integral. Ciência e Tecnologia de Alimentos, v. 26, n. 2, p. 428-433, 2006.

BISPO, E. S.; FERREIRA, V. L. P.; SANTANA, L. R. R.; YOTSUYANAGI, K. Perfil sensorial de pó de cacau (Theobroma cacao L.) alcalinizado. Ciência e Tecnologia de Alimentos, v. 25, n. 2, p. 375-381, 2005.

BRASIL. Agência Nacional de Vigilância Sanitária. Decreto n 2.314 , de 4 de setembro de 1997. Regulamenta a Lei no 8.918, de 14 de julho de 1994, que dispõe sobre a padronização, a classificação, o registro, a inspeção, a produção e a fiscalização de bebidas. Diário Oficial da União, Brasília, DF, 05 set. 1997.
BRASIL. Ministério da Agricultura. Secretaria de Defesa Agropecuária. Instrução Normativa DAS no 30, de 27 set. 1999. Regulamento técnico para fixação dos padrões de identidade e qualidade para a bebida dietética e a de baixa caloria. Diário Oficial da União, Brasília, DF, 29 set. 1999.

CALVO, C.; DURÁN, L. Propiedades Físicas II - Ópticas y color. In: AGUILERA, J. M. Temas en Tecnología de Alimentos. México: Ed. Instituto Politécnico Nacional, v. I, p. 261-288, 1997.

CARDELLO, H. M. A. B.; FARIA, J. B. Análise descritiva quantitativa da aguardente de cana durante o envelhecimento em tonel de carvalho (Quercus alba L.). Ciência e Tecnologia de Alimentos, v. 18, n. 2, p. $169-175,1998$.

CARDELLO, H. M. A. B. Influência do exercício físico na aceitação de chá mate adoçado com diferentes edulcorantes. In: SIMPÓSIO LATINO AMERICANO DE CIÊNCIA DE ALIMENTOS, 4., 2001, Campinas. Anais... Campinas: SBCTA, 2001. v. 1, p. 254-254.

CARDOSO, J. M. P.; CARDELLO, H. M. A. B. Determinação da doçura ideal, doçura equivalente, aceitação e perfil sensorial de chá mate quente com diferentes edulcorantes. In: CONGRESSO INTERNO DE INICIAÇÃO CIENTÍFICA, 9, 2003, Campinas. Anais... Campinas: Unicamp, 2003. Disponível em: <http://www. prp.unicamp.br/pibic/congressos/xicongresso/cdrom/html/FEA. html>. Acesso em: 29 abr. 2007.

CARDOSO, J. M. P.; BATTOCHIO, J. R.; CARDELLO, H. M. A. B. Equivalência de dulçor e poder edulcorante de edulcorantes em função da temperatura de consumo em bebidas preparadas com chá-mate em pó solúvel. Ciência e Tecnologia de Alimentos, v. 24, n. 3, p. 448-452, 2004.

MACFIE, H.; BRATCHELL, N. Designs to balance the effect of order of presentation and first-order carry-over effects in hall tests. Journal of Sensory Studies, v. 4, n. 2, p. 129-148, 1989.

MEILGAARD, M.; CIVILLE, G. V.; CARR, B. T. Sensory evaluation techniques. $3 \mathrm{ed}$. New York: CRC, 1999. $281 \mathrm{p}$.

MORAES, P. C. B. T. Avaliação de iogurtes líquidos comerciais sabor morango: estudo de consumidor e perfil sensorial. Campinas. 128p. Dissertação - (Mestrado em Alimentos e Nutrição), Faculdade de Engenharia de Alimentos, Universidade Estadual de Campinas - UNICAMP.

MOSKOWITZ, H. R. Product testing and sensory evaluation of foods. Westport: Food and Nutrition Press, 1983. 605 p.

SANTANA, L. R. R.; SANTOS, L. C. S.; NATALICIO, M. A. et al. Perfil sensorial de iogurte light, sabor pêssego. Ciência e Tecnologia de Alimentos, v. 26, n. 3, p. 619-625, 2006.

SAS. SAS USERS' GUIDE: statistics. 2 ed. Cary: SAS Institute, 2003. v. 8.

STONE, H.; SIDEL, J. L. Sensory Evaluation Practices. 2 ed. London: Academic Press, 1993. 336p.

VERRUMA-BERNARDI, M. R.; SPOTO, M. H. F. Efeito da radiação gama sobre o perfil sensorial de suco de laranja. Ciência e Tecnologia de Alimentos, v. 23, n. 1, p. 28-32, 2003.

VICKERS, Z. Sensory specific satiety in lemonade using a just right scale for sweetness. Journal of Sensory Study, v. 3, n. 1, p. 1-8, 1988. 